Schermer, T.R., Malbon, W., Morgan, M., Smith, M., Crockett, A.J. Chronic respiratory conditions in a cohort of metropolitan fire-fighters: associations with occupational exposure and quality of life. NPJ Primary Care Respiratory Medicine: 2017, 27(55), 919-928

\begin{tabular}{|l|l|}
$\begin{array}{l}\text { Postprint } \\
\text { Version }\end{array}$ & 1.0 \\
\hline Journal website & https://link.springer.com/article/10.1007\%2Fs00420-014-0935-8 \\
\hline Pubmed link & $\underline{\text { https://www.ncbi.nlm.nih.gov/pubmed/?term=24570328 }}$ \\
\hline DOI & $10.1007 /$ s00420-014-0935-8
\end{tabular}

This is a NIVEL certified Post Print, more info at http://www.nivel.eu

\title{
Chronic respiratory conditions in a cohort of metropolitan fire-fighters: associations with occupational exposure and quality of life
}

TJARD R. SCHERMER • WINIFRED MALBON • MICHAEL MORGAN • MICHAEL SMITH • ALAN J. CROCKETT

\begin{abstract}
Objectives To assess the prevalence of chronic respiratory conditions in metropolitan fire-fighters and to study associations between occupational exposure, use of respiratory protection and health-related quality of life (HRQoL) in fire-fighters with and without chronic respiratory conditions.

Methods Cross-sectional cohort analysis: Respiratory symptoms, medical conditions, occupational tasks and exposures and consistency of using respiratory protection were inquired by questionnaire. The SF12_V2 Health Survey was used to measure physical (PCS-12) and mental (MCS-12) HRQoL. Fire-fighters were categorised in subgroups: asthma; COPD/emphysema/chronic bronchitis; no chronic respiratory conditions; and as being 'not involved' or 'involved' in fire-fighting tasks, the latter further categorised as 'consistent' or 'inconsistent' use of respiratory protection. PCS-12 and MCS-12 scores were compared between subgroups and categories using linear regression.

Results Five hundred and seventy fire-fighters were analysed, 24 (4 \%) fulfilled the criteria for asthma, 39 (7\%) for COPD/emphysema/chronic bronchitis. Firefighters with asthma were older than those in the other two subgroups and had been employed in the fire service longer. Respiratory subgroups did not differ in their involvement in fire-fighting tasks. Ninety-one percent of fire-fighters reported relevant occupational exposure in the past year. Mean PCS-12 scores for fire-fighters with no chronic respiratory conditions, asthma and COPD/emphysema/ bronchitis were 52.0 (SD 6.9), 47.0 (8.5) and 48.1 (9.4).

For PCS-12 (but not for MCS-12), interaction between having a chronic respiratory condition and inconsistent use of respiratory protection during fire knockdown was observed (pl0.001).

Conclusions Ten percent of metropolitan fire-fighters reported underlying chronic respiratory conditions. Presence of such a condition in combination with
\end{abstract}


Schermer, T.R., Malbon, W., Morgan, M., Smith, M., Crockett, A.J. Chronic respiratory conditions in a cohort of metropolitan fire-fighters: associations with occupational exposure and quality of life. NPJ Primary Care Respiratory Medicine: 2017, 27(55), 919-928

suboptimal protection from inhaled exposures may lead to poorer physical HRQoL.

\section{INTRODUCTION}

Fire-fighters may be at increased risk of adverse health effects due to exposure to all kinds of potentially harmful substances during their professional duties. Providing respiratory protection devices to fire-fighters to prevent inhalation of smoke, fumes and particles has become standard policy in fire departments around the world, although in reality, the devices may not always be optimally used (Greven et al. 2011; Schermer et al. 2010, 2014).

Even while recruits for fire services are selected based on their physical fitness and good general health (Anonymous 2010; Duffy et al. 2010), some fire-fighters may have an underlying chronic respiratory condition or develop such a condition during their professional careers. Previous research has mainly focused on the association between fire-fighters' occupational exposures and new-onset chronic respiratory conditions. For instance, follow-up of fire-fighters (and other emergency service workers) responding to the World Trade Center (WTC) disaster has shown that they are at an increased risk of developing asthma and other physician-diagnosed respiratory conditions in subsequent years (Kim et al. 2012; Webber et al. 2011; Wheeler et al. 2007). However, studies looking at the health status of firefighters once they have developed a chronic respiratory condition do not seem to have been reported so far. What has been reported though is that being exposed to smoke and other airborne matters increases fire-fighters' bronchial hyperresponsiveness in the short term (Chia et al. 1990; Greven et al. 2012; Kinsella et al. 1991; Loke et al. 1980; Miedinger et al. 2007a; Sherman et al. 1989) as well as in the longer term (Banauch et al. 2003; Loke et al. 1980; Prezant et al. 2002), and may also lead to reduced lung function (Burgess et al. 2001; Greven et al. 2011; Liu et al. 1992; Loke et al. 1980, 1992; Mustajbegovic et al. 2001). It has previously been shown that fire-fighters who are incompliant with regard to consistent use of respiratory protection devices while being exposed showed an increased risk of accelerated FEV1 decline (Schermer et al. 2010, 2014; Tepper et al. 1991). Knowing this, it seems all the more important for firefighters who have an underlying chronic respiratory condition to use their protection devices consistently, as they may be more likely to experience negative health consequences when inhaling potentially harmful substances during their professional duties.

The aims of the current study were therefore to (1) assess the prevalence of chronic respiratory conditions in our cohort of South Australian metropolitan fire-fighters and (2) relate self-reported occupational exposure and use of respiratory protection devices to health-related quality of life in fire-fighters with and without chronic respiratory conditions. We hypothesised that fire-fighters with an underlying chronic respiratory condition would have poorer health-related quality of life when they are occupationally exposed to inhaled substances than those with no such underlying condition. 
Schermer, T.R., Malbon, W., Morgan, M., Smith, M., Crockett, A.J. Chronic respiratory conditions in a cohort of metropolitan fire-fighters: associations with occupational exposure and quality of life. NPJ Primary Care Respiratory Medicine: 2017, 27(55), 919-928

\section{METHODS}

\section{Study design and subjects}

The study was a cross-sectional analysis in an ongoing prospective dynamic cohort study in South Australian metropolitan fire-fighters, the South Australian Metropolitan Fire Service (SAMFS) study (Schermer et al. 2010). To date, the SAMFS study consists of three rounds of measurements: in 2007/2008 (stage 1), 2010/2011 (stage 2) and 2012/2013 (stage 3). The current analysis was based on the second and third rounds of data collection only, as the first round did not include items on occupational exposures or use of respiratory protection devices. Subsequently, 458 fire-fighters took part in stage 2 and 461 in stage 3 . There were both dropouts and new enrolees at each of the stages 2 and 3, with some who had missed round 2 returning in stage 3 . Baseline lung function values and their percentage predicted values were lower in fire-fighters who did not participate in a next stage of data collection (Schermer et al. 2014). One hundred and ninety-eight fire-fighters provided information at both time points. In these cases, only the most recent information (i.e. from 2012/2013) was used, so each fire-fighter could only contribute data from one stage. At the start of the study, the SAMFS maintained staff that included 729 full-time fire-fighters, all but one (99.6\%) Caucasians. The overall participation rate of the fire-fighters invited for the two rounds of measurements was $64.3 \%$.

The current analysis was funded by the SAMFS and the University of Adelaide and received ethics approval from the University of Adelaide Human Research Ethics Committee (H-057-2007). All study participants gave written informed consent.

\section{Data collection and measurements}

Information regarding demographic characteristics, smoking, respiratory symptoms, doctor-diagnosed respiratory, cardiovascular and other medical conditions, cardiovascular risk factors (i.e. hypertension, hypercholesterolemia), occupational exposures and use of respiratory protection devices was collected using a studyspecific questionnaire.( Schermer et al. 2010, 2014) Part of the items in the questionnaire were taken from the 'Heart Disease among Firefighters' study from the University of British Columbia, Vancouver, Canada (http://hdfirefighters.spph.ubc.ca/ heart-disease-among-firefighters/welcome).

The SAMFS has been using various types of compressed air/decant systems since the early 1970s for respiratory protection of their fire-fighters. Since 1997 until present (so during the observation period of the current study), Air- Maxx self-contained breathing apparatus systems (MSA

Auer, Berlin, Germany) are used. The study questionnaire also contained questions about whether or not the firefighters had been exposed to the following substances in the last 12 months: smoke (including particulate matter); vapours or fumes; organic solvents; organic dusts; or inorganic dusts. Other items in the questionnaire inquired whether and how frequently fire-fighters had been involved in common fire-fighting tasks (knockdown, overhaul) and the types of fires (residential, car, shops/offices, dump/ waste, industrial, bush and marine) they had attended during the last 12 months. We also inquired how often the fire-fighters had usually worn their respiratory protection during these tasks in that same period.

The SF-12_V2 Health Survey (QualityMetric, Lincoln, RI, USA) was used to measure generic health-related quality of life. The SF-12 contains eight subscales 
Schermer, T.R., Malbon, W., Morgan, M., Smith, M., Crockett, A.J. Chronic respiratory conditions in a cohort of metropolitan fire-fighters: associations with occupational exposure and quality of life. NPJ Primary Care Respiratory Medicine: 2017, 27(55), 919-928

(Ware et al. 1996): physical functioning (2 items); role limitations due to physical problems ( 2 items); bodily pain ( 1 item); general health perceptions ( 1 item); vitality (1 item); social functioning (1 item); role limitations due to emotional problems (2 items); and mental health ( 2 items). Based on these items, two summary scores are calculated: the physical (PCS-12) and the mental (MCS-12) component summary scores. PCS-12 and MCS-12 scores have a range of 0-100 (a higher score indicating better health-related quality of life) and were designed to have a mean score of 50 and a standard deviation of 10 in a representative sample of the US population. The psychometric properties and factor structure of the SF-12 have been examined in several studies worldwide, the results of which showing that the instrument is a reliable and valid measure that can be used in a variety of study populations, among which are various occupational groups (Ross et al. 2007; van den Berg et al. 2008) and subjects with chronic respiratory conditions (Adams et al. 2003; Katz et al. 2005).

Spirometry in the fire-fighters was performed using a Masterscreen_spirometer (Viasys Healthcare/Cardinal Health, Würzburg, Germany) following 2005 international recommendations for spirometry (Miller et al. 2005). All spirometry tests were performed by the same research nurse (WM). Predicted normal values for the forced expiratory volume in one second (FEV1) and forced vital capacity (FVC) used were those published by Gore et al. (1995).

\section{Definitions of chronic conditions and consistency in respiratory protection}

Based on the questionnaire data, the following subgroups of fire-fighters in terms of their respiratory health were defined (further referred to as 'respiratory health subgroups'): - Asthma doctor-diagnosed asthma plus an asthma attack in the previous 12 months; or doctor-diagnosed asthma and current use of asthma medication; or no doctordiagnosed asthma reported, but had experienced asthma attacks before and currently using asthma medication.

- COPD, emphysema, chronic bronchitis doctor-diagnosed COPD, emphysema or chronic bronchitis that was still persisting; and/or coughing up phlegm from the chest on most days for as much as 3 months each year for at least 2 years (Siafakas et al. 1995).

- No chronic respiratory conditions all other fire-fighters in the study sample. Participants recorded other medical conditions they might suffer from in a free-text field. The reported conditions were post hoc coded into the following categories: cardiovascular (myocardial infarction, angina pectoris, heart failure, stroke); diabetes mellitus; chronic locomotor conditions; recent pneumonia; and 'other' (which included single cases of prostate cancer; Crohn's disease; renal dysfunction; myeloma; sleep apnoea; and mental illness).

To express fire-fighters' consistency in using respiratory protection when involved in common fire-fighting tasks, we combined 'often' (60-80\% of the time) and 'frequent' (80-100\%) use to reflect 'consistent use', and 'never', 'rarely' (140\%) and 'some of the time' (40-60\%) as 'inconsistent use'. Because knockdown (i.e. putting out fires) is the commonest fire-fighting task and probably also the exposure of greatest respiratory health relevance, we focused on consistency of respiratory protection during this particular task in the further analyses. Finally, three 'exposure protection categories' were defined: - fire-fighters who reported not to have been involved in knockdown; • fire-fighters involved in knockdown who reported 
Schermer, T.R., Malbon, W., Morgan, M., Smith, M., Crockett, A.J. Chronic respiratory conditions in a cohort of metropolitan fire-fighters: associations with occupational exposure and quality of life. NPJ Primary Care Respiratory Medicine: 2017, 27(55), 919-928

'consistent use' of respiratory protection; and • fire-fighters involved in knockdown who reported 'inconsistent use' of respiratory protection.

\section{Statistical analysis}

Linear regression analyses, v2 and Fisher's exact tests were used to compare characteristics between the three respiratory subgroups. Logistic regression analysis [with correction for age and body mass index (BMI)] was used to compare the presence of cardiovascular risk factors between the subgroups. PCS-12 and MCS-12 component summary scores were compared using linear regression models, in which presence of a chronic respiratory condition and exposure protection category were included as independent variables. Because the objective of this part of the analysis was to test for differential PCS-12 and MCS- 12 scores between fire-fighters with and without underlying chronic respiratory conditions who were either sufficiently protected during occupational exposure or not, interaction terms that combine these two independent variables were included in the regression models (see Table 3 for further details). Age, BMI and presence of other relevant medical conditions that are known to influence health-related quality of life were therefore entered as covariates. Because of the relatively small numbers of fire-fighters in the different exposure protection categories in the asthma and COPD/emphysema/bronchitis subgroups, these two subgroups were combined in this final part of the analysis.

SPSS version 20.0 was used for all analyses. $p$ values 10.05 were considered statistically significant.

\section{[TABLE 1]}

\section{RESULTS}

\section{Study population and chronic conditions}

A total of 592metropolitan fire-fighters weremeasured during the second, third or both stages of the MFS study. Essential questionnaire items regarding the presence of chronic respiratory conditions and symptoms were missing for 8 firefighters. These were excluded from further analysis, as were 14 new recruits to the fire service. This resulted in a final sample of 570 metropolitan fire-fighters to be analysed.

Twenty-four fire-fighters ( $4 \%$ ) fulfilled the criteria for asthma. In this subgroup, all but two (92\%) indicated to have doctor-diagnosed asthma and all but one (96\%) were currently using asthma medication: 13 inhaled bronchodilators only and 10 inhaled bronchodilators combined with inhaled corticosteroids. Thirty-nine firefighters $(6.8 \%)$ fulfilled the criteria for COPD, emphysema and/or chronic bronchitis ( 5 of which also fulfilled the criteria for asthma and were analysed in the asthma subgroup). Of the 34 firefighters in this subgroup, 11 reported doctor-diagnosed COPD, emphysema or chronic bronchitis. The remaining 23 fire-fighters fulfilled the widely used symptom-based definition of chronic bronchitis. None of the firefighters in the COPD/emphysema/bronchitis subgroup reported use of respiratory medication.

Table 1 shows demographic and clinical characteristics of the three subgroups. With a mean age of 49.2 (SD 9.0)

years, the fire-fighters in the asthma subgroup were older than those in the other two subgroups $(p=0.029)$. They had also been employed in the fire service for the 
Schermer, T.R., Malbon, W., Morgan, M., Smith, M., Crockett, A.J. Chronic respiratory conditions in a cohort of metropolitan fire-fighters: associations with occupational exposure and quality of life. NPJ Primary Care Respiratory Medicine: 2017, 27(55), 919-928

longest period of time (24.6 (SD 10.0) years); p10.001). After correcting for age, the subgroups did not differ with regard to lung function indices (Table 1).

Overall, $63(11.1 \%)$ fire-fighters reported one or more other relevant medical conditions, the most common ones being chronic locomotor $(n=35)$ and cardiovascular $(n=14)$ conditions. None of the fire-fighters in the asthma subgroup and only 1 in the COPD/emphysema/bronchitis subgroup reported locomotor conditions. The overall number of fire-fighters with cardiovascular conditions was too small to allow statistical testing of differences between the subgroups: 6 cases $(18 \%)$ in the COPD/emphysema/ bronchitis subgroup, 1 (4\%) in the asthma subgroup and $7(1 \%)$ in the subgroup with no chronic respiratory conditions. Compared to the subgroup with no chronic respiratory conditions, both the asthma and the COPD/ emphysema/bronchitis subgroups showed higher odds of cardiovascular risk factors being present: $\mathrm{OR}=2.5(95 \% \mathrm{CI} 1.0,6.4)$ and $\mathrm{OR}=2.8$ (95\% CI 1.43, 6.3), after adjusting for age and BMI.

\section{[TABLE 2]}

\section{Occupational exposure and use of respiratory protection}

The respiratory health subgroups did not differ with regard to their involvement in common fire-fighting tasks in the past 12 months, nor did those involved in these tasks differ in their consistency of using respiratory protection during these tasks (Table 2). The same was true for attendance to different types of fires (Table 2). Overall, $91 \%$ of the firefighters reported to have been exposed to smoke in the past 12 months, $83 \%$ to vapours or fumes, $48 \%$ to inorganic dusts, $43 \%$ to organic dusts and $33 \%$ to organic solvents, but no differences between the subgroups were observed (Table 2). Nine fire-fighters in the asthma subgroup (38\%) reported to have been exposed to smoke or fumes that had made them sick and/or required medical attention because of it in the past 12 months, compared to $7(21 \%)$ in the COPD/emphysema/bronchitis subgroup and $85(17 \%)$ in the non-respiratory subgroup (v2 test: $\mathrm{p}=0.031$ ).

\section{Comparison of SF-12 scores between subgroups}

Overall mean PCS-12 scores for the subgroups with no chronic respiratory conditions, asthma and COPD/emphysema/ bronchitis were 52.0 (6.9), 47.0 (8.5) and 48.1 (9.4), respectively. The corresponding figures for MCS-12 scores were 52.7 (7.6), 52.1 (7.8) and 49.1 (8.0). Figure 1 shows the mean values for the PCS-12 and MCS-12 scale scores for the respective respiratory health subgroups of firefighters in relation to the exposure protection categories.

Table 3 shows the results of the linear regression models.

Neither having a chronic respiratory condition nor being involved in knockdown or inconsistent use of protection

was associated with the PCS-12 score. However, the b coefficient of the interaction term 'chronic respiratory condition * inconsistent use of respiratory protection' was statistically significantly different from zero ( $p \backslash 0.001$ ), which implies that the firefighters in the combined asthma and COPD/emphysema/bronchitis subgroups who reported inconsistent use of respiratory protection on average had $5.54(95 \% \mathrm{CI}$ $7.95 ; 3.13)$ points lower PCS-12 scores than those reporting consistent use of protection. This was not the case for the interaction term 'Chronic respiratory condition * not involved in knockdown' $(\mathrm{p}=0.536)$, indicating that fire-fighters with 
Schermer, T.R., Malbon, W., Morgan, M., Smith, M., Crockett, A.J. Chronic respiratory conditions in a cohort of metropolitan fire-fighters: associations with occupational exposure and quality of life. NPJ Primary Care Respiratory Medicine: 2017, 27(55), 919-928

a chronic respiratory condition who are not involved in knockdown have similar PCS-12 scores as those who are involved but use their respiratory protection devices consistently. As expected, age, BMI and having other relevant medical conditions were all associated with PCS-12 score (p10.001). For the MCS-12, neither the b coefficients of having a chronic respiratory condition, nor being involved or being protected from occupational exposure, nor the interaction terms differed from zero (Table 3). Presence of other relevant medical conditions was statistically significantly associated with (lower) MCS-12 scores (-4.59, $95 \%$ CI $-6.65 ;-2.53$ ) whereas older age and higher BMI were not. Excluding the 13 female fire-fighters from the analyses did not significantly change the regression coefficients or their confidence intervals (results not shown).

\section{DISCUSSION}

The main objective of this study was to compare occupational exposures, use of respiratory protective devices and their combined association with health-related quality of life between metropolitan fire-fighters with and without self-reported chronic respiratory conditions. Overall, $10 \%$ of the fire-fighters reported to either have been diagnosed with a chronic respiratory condition (asthma, COPD, emphysema and chronic bronchitis) or reported persistent symptoms of chronic bronchitis. On average, fire-fighters with chronic respiratory conditions were older and had more years of employment in the fire service than those with no chronic respiratory conditions. Those with chronic respiratory conditions were no different with regard to their involvement in regular fire-fighting tasks or attendance to common types of fires, nor in their use of respiratory protection during these tasks or fires. Fire-fighters with asthma reported to have been sick from being exposed twice as often in the past year as those with COPD, emphysema or chronic bronchitis or those without respiratory conditions. After correction for other factors that are known to reduce health-related quality of life (i.e. older age, overweight and having other medical problems), firefighters with chronic respiratory conditions that did not use their protective devices consistently to prevent themselves from inhaled occupational exposures during fire knockdown showed lower physical SF-12 component summary scores than those who did use their respiratory protection consistently. Presence of other medical conditions was associated with (poorer) health-related quality of life in both the physical and the mental domains.

\section{Comparison with existing literature}

We have previously reported an association between suboptimal use of respiratory protection and risk of accelerated lung function decline from the same fire-fighter cohort (Schermer et al. 2010, 2014), but did not analyse the SF-12 data or subgroups of fire-fighters with or without chronic respiratory conditions. We identified three other studies that have looked at fire-fighters' health-related quality of life. Two of these studies concerned follow-up of firefighters after major disasters, i.e. the terrorist attack on the WTC in New York in 2001(Berninger et al. 2010) and an airplane crash in Amsterdam in 1992 (Slottje et al. 2007).

In the latter study, professional fire-fighters with disaster exposure reported a significantly poorer physical healthrelated quality of life and vitality compared to their nonexposed colleagues, but associations between these health outcomes and fire-fighters' pre-existing (respiratory) conditions were not analysed (Huizink et al. 2006). The WTC study showed that fire-fighters with chronic cough syndrome had 
Schermer, T.R., Malbon, W., Morgan, M., Smith, M., Crockett, A.J. Chronic respiratory conditions in a cohort of metropolitan fire-fighters: associations with occupational exposure and quality of life. NPJ Primary Care Respiratory Medicine: 2017, 27(55), 919-928

poorer health-related quality of life, which persisted years after their exposure to WTC dust (Berninger et al. 2010). However, in this case, the extreme circumstances and exposure during the disaster are quite different from the ones that fire-fighters will usually be confronted with during their regular duties. A third study, which was based on a small cohort $(n=112)$ of professional fire-fighters in the USA, reported associations between health-related quality of life and lifestyle behaviour and psychosomatic well-being, but did not investigate associations with respiratory conditions or occupational exposure (Carey et al. 2011).

A previous report based on the data from our fire-fighter cohort showed better general health, better lung health and similar mental health compared to general population controls (Schermer et al. 2010). In the current analysis, the mean SF12 physical component score of the fire-fighters with asthma (47.0 points) is very similar to the score that has been observed in individuals diagnosed with asthma (47.2 points) in the South Australian population (Avery et al. 2004). In contrast, the fire-fighters who reported COPD, emphysema or chronic bronchitis had much higher PCS-12 scores than individuals from the general South Australian population with these conditions (48.1 points versus 36.7 points) (Avery et al. 2004).

\section{[FIGURE 1]}

Presumably, this difference is due to differences between the respective cohorts in terms of age, disease severity and definitions used to identify chronic respiratory conditions, but it might also be due to a 'healthy worker effect' (i.e. persons with chronic respiratory conditions who are still in good health and shape may be more likely to work as fire-fighters than those in worse health).

\section{[TABLE 3]}

Investigators from Switzerland found that professional fire-fighters reported more respiratory symptoms at work compared with general population controls (Miedinger et al. 2007a) and a prevalence of asthma that was slightly higher than in our cohort (6 vs $4 \%$, respectively) (Miedinger et al. 2007b). Interestingly, this Swiss study also showed that asthma seemed considerably underdiagnosed in the fire-fighter cohort (Miedinger et al. 2007b). Unfortunately, we were not able to verify this in our cohort, as we did not perform bronchial challenge tests to identify asthma.

\section{Strengths and limitations}

A particular strength of our study is the size of the cohort and the detailed information from the study questionnaire regarding participants' occupational exposures, respiratory symptoms and medical conditions.

However, even while our cohort consisted of a substantial number of fire-fighters, the number with chronic respiratory conditions was - as could be expectedrelatively small (58 in total). This limits the statistical power and thus possibilities for more in-depth analyses of, for instance, differences between the fire-fighters with doctor-diagnosed COPD, emphysema or chronic bronchitis and those that were considered to have chronic bronchitis based on the respiratory symptom items in the questionnaire.

Our data about involvement in fire-fighter tasks and exposures to potentially harmful inhaled substances were limited to fire-fighters' self-reports only, and the questionnaire items related to fire-fighters' tasks involved in and use of respiratory 
Schermer, T.R., Malbon, W., Morgan, M., Smith, M., Crockett, A.J. Chronic respiratory conditions in a cohort of metropolitan fire-fighters: associations with occupational exposure and quality of life. NPJ Primary Care Respiratory Medicine: 2017, 27(55), 919-928

protection during these tasks have not been validated yet. Clearly, we would have preferred to have more comprehensive information regarding length of time spent in exposed jobs, number of responses and actual observations of fire-fighters' use of respiratory protection devices at our disposal, but in the current study, it was not feasible to collect this kind of data. The same limitation holds for the fire-fighters' self-reported information on respiratory and other medical conditions. For instance, access to their medical records would have allowed for more detailed diagnostic information about the fire-fighters' medical conditions.

Because of its observational, cross-sectional design, no causal inferences can be made from the current study. It would require an intervention study in fire-fighters with underlying chronic respiratory conditions to establish the effect of improving their use of respiratory protection devices on relevant outcomes like health-related quality of life and lung function decline.

In conclusion, we found that 10 percent of metropolitan fire-fighters had underlying chronic respiratory conditions (asthma, COPD, emphysema and chronic bronchitis). There appears to be an association between the presence of such a condition and physical health-related quality of life in fire-fighters who do not seem to optimally protect themselves from exposure to inhaled substances that come with the job. This finding suggests that fire services should pay specific attention to consistent use of respiratory protection devices in employees who have underlying chronic respiratory conditions but are nonetheless exposed to inhaled matters when fulfilling their professional duties.

Regular monitoring of fire-fighters with regard to respiratory conditions should also be considered, since previous studies have shown that there might be a problem of underdiagnosis as well.

\section{Acknowledgments}

Acknowledgement is made of the generosity of the South Australian Metropolitan Fire Service (SAMFS) fire-fighters in giving their time and effort, and of the contribution to the study by the SAMFS staff. The authors very much appreciate the preparatory work for the study performed by Guillaume Dujardin and Christine Holton, the statistical advice provided by Michelle Lorimer, the support in the data entry and processing by Daniel Blakeley, and the support in participant recruitment, planning and logistics by Commander Andrew Lindsey. The study was funded by the SAMFS and The University of Adelaide.

\section{Conflict of interest}

The authors declare that they have no conflict of interest.

\section{REFERENCES}

Adams RJ et al (2003) Underdiagnosed asthma in South Australia. Thorax 58(10):846-850 Anonymous (2010) AFAC Medical Guidelines for Fire and Emergency Service Workers. Australasian Fire and Emergency Service Authorities Council

Avery J, Dal Grande E, Taylor A (2004) Quality Of Life in South Australia as Measured by the SF12 Health Status Questionnaire. Population Norms For 2003, Trends From 19972003. Department of Human Services, Population Research and Outcome Studies Unit, South Australia

Banauch Gl et al (2003) Persistent hyperreactivity and reactive airway dysfunction in firefighters at the World Trade Center. Am J Respir Crit Care Med 168(1):54-62. doi:10.1164/rccm.200211-13290C11-13290C 
Schermer, T.R., Malbon, W., Morgan, M., Smith, M., Crockett, A.J. Chronic respiratory conditions in a cohort of metropolitan fire-fighters: associations with occupational exposure and quality of life. NPJ Primary Care Respiratory Medicine: 2017, 27(55), 919-928

Berninger A et al (2010) Quality of life in relation to upper and lower respiratory conditions among retired 9/11-exposed firefighters with pulmonary disability. Qual Life Res 19(10):1467-1476. doi:10.1007/s11136-010-9710-9

Burgess $\mathrm{JL}$ et al (2001) Adverse respiratory effects following overhaul in firefighters. J Occup Environ Med 43(5):467-473

Carey MG, Al-Zaiti SS, Dean GE, Sessanna L, Finnell DS (2011) Sleep problems, depression, substance use, social bonding, and quality of life in professional firefighters. $J$ Occup Environ Med 53(8):928-933. doi:10.1097/JOM.0b013e318225898f

Chia KS, Jeyaratnam J, Chan TB, Lim TK (1990) Airway responsiveness of firefighters after smoke exposure. Br J Ind Med 47(8):524-527

Duffy R, Berman A, Prezant D (2010) Respiratory diseases and the fire service. International Association of Fire Fighters, Washington, United States of America

Gore CJ, Crockett AJ, Pederson DG, Booth ML, Bauman A, Owen N (1995) Spirometric standards for healthy adult lifetime nonsmokers in Australia. Eur Respir J 8(5):773-782

Greven F, Krop E, Spithoven J, Rooyackers J, Kerstjens H, Heederik D (2011) Lung function, bronchial hyperresponsiveness, and atopy among firefighters. Scand J Work Environ Health 37(4):325-331. doi:10.5271/sjweh.3153

Greven FE et al (2012) Acute respiratory effects in firefighters. Am J Ind Med 55(1):54-62. doi:10.1002/ajim.21012

Huizink AC et al (2006) Long term health complaints following the Amsterdam air disaster in police officers and fire-fighters. Occup Environ Med 63(10):657-662. doi:10.1136/oem.2005.024687

Katz PP et al (2005) Functioning and psychological status among individuals with COPD. Qual Life Res 14(8):1835-1843. doi:10. 1007/s11136-005-5693-3

$\mathrm{Kim} \mathrm{H}$ et al (2012) Increased rates of asthma among World Trade Center disaster responders. Am J Ind Med 55(1):44-53. doi:10. 1002/ajim.21025

Kinsella J, Carter R, Reid WH, Campbell D, Clark CJ (1991) Increased airways reactivity after smoke inhalation. Lancet 337(8741):595-597

Liu D, Tager IB, Balmes JR, Harrison RJ (1992) The effect of smoke inhalation on lung function and airway responsiveness in wildland fire fighters. Am Rev Respir Dis 146(6):1469-1473

Loke J, Farmer W, Matthay RA, Putman CE, Smith GJ (1980) Acute and chronic effects of fire fighting on pulmonary function. Chest 77(3):369-373

Loke J, Abrams C, Virgulto J (1992) Lung function in fire fighters. Conn Med 56(4):179-183 Miedinger $\mathrm{D}$ et al (2007a) Respiratory symptoms, atopy and bronchial hyperreactivity in professional firefighters. Eur Respir J 30(3):538-544. doi:10.1183/09031936.00015307

Miedinger D, Chhajed PN, Tamm M, Stolz D, Surber C, Leuppi JD (2007b) Diagnostic tests for asthma in firefighters. Chest 131(6):1760-1767. doi:10.1378/chest.06-2218

Miller MR et al (2005) Standardisation of spirometry. Eur Respir J 26(2):319-338. doi:10.1183/09031936.05.00034805

Mustajbegovic $\mathrm{J}$ et al (2001) Respiratory function in active firefighters. Am J Ind Med 40(1):55-62. doi:10.1002/ajim.1071

Prezant DJ et al (2002) Cough and bronchial responsiveness in firefighters at the World Trade Center site. N Engl J Med 347(11):806-815.

doi:10.1056/NEJMoa021300NEJMoa021300

Ross JA, Macdiarmid JI, Osman LM, Watt SJ, Godden DJ, Lawson A (2007) Health status of professional divers and offshore oil industry workers. Occup Med (Lond) 57(4):254-261. doi:10. 1093/occmed/kqm005

Schermer TR et al (2010) Lung function and health status in metropolitan fire-fighters compared to general population controls. Int Arch Occup Environ Health 83(7):715-723

Schermer TR, Malbon W, Adams R, Morgan M, Smith M, Crockett AJ (2014) Change in lung function over time in male metropolitan fire-fighters and general population controls. A 3year follow-up study. J Occup Health 55(4):267-275

Sherman CB et al (1989) Firefighting acutely increases airway responsiveness. Am Rev Respir Dis 140(1):185-190. doi:10. 1164/ajrccm/140.1.185

Siafakas NM et al (1995) Optimal assessment and management of chronic obstructive pulmonary disease (COPD). The European Respiratory Society Task Force. Eur Respir J 8(8):1398-1420 
Schermer, T.R., Malbon, W., Morgan, M., Smith, M., Crockett, A.J. Chronic respiratory conditions in a cohort of metropolitan fire-fighters: associations with occupational exposure and quality of life. NPJ Primary Care Respiratory Medicine: 2017, 27(55), 919-928

Slottje $\mathrm{P}$ et al (2007) Health-related quality of life of firefighters and police officers 8.5 years after the air disaster in Amsterdam. Qual Life Res 16(2):239-252. doi:10.1007/s11136-0069006-2

Tepper A, Comstock GW, Levine M (1991) A longitudinal study of pulmonary function in fire fighters. Am J Ind Med 20(3):307-316

van den Berg TI, Alavinia SM, Bredt FJ, Lindeboom D, Elders LA, Burdorf A (2008) The influence of psychosocial factors at work and life style on health and work ability among professional workers. Int Arch Occup Environ Health 81(8):1029-1036. doi:10.1007/s00420-007-0296-7

Ware J Jr, Kosinski M, Keller SD (1996) A 12-Item Short-Form Health Survey: construction of scales and preliminary tests of reliability and validity. Med Care 34(3):220-233

Webber MP et al (2011) Physician-diagnosed respiratory conditions and mental health symptoms 7-9 years following the World Trade Center disaster. Am J Ind Med 54(9):661671. doi:10. 1002/ajim.20993

Wheeler K et al (2007) Asthma diagnosed after 11 September 2001 among rescue and recovery workers: findings from the World Trade Center Health Registry. Environ Health Perspect 115(11):1584-1590. doi:10.1289/ehp.10248 
Schermer, T.R., Malbon, W., Morgan, M., Smith, M., Crockett, A.J. Chronic respiratory conditions in a cohort of metropolitan fire-fighters: associations with occupational exposure and quality of life. NPJ Primary Care Respiratory Medicine: 2017, 27(55), 919-928

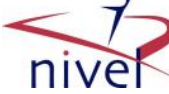

\section{TABLES AND FIGURES}

Table 1 Characteristics of the total fire-fighter cohort $(n=570)$ and for the subgroups with self-reported chronic respiratory conditions

\begin{tabular}{|c|c|c|c|c|c|c|c|}
\hline \multirow[b]{2}{*}{$n(\%)$} & \multicolumn{2}{|c|}{ No chronic respiratory condition } & \multicolumn{2}{|c|}{ Asthma $^{\mathrm{a}}$} & \multicolumn{2}{|c|}{ COPD, emphysema or bronchitis ${ }^{\mathrm{a}}$} & \multirow[t]{2}{*}{$p$} \\
\hline & 512 & $(90)$ & 24 & (4) & 34 & (6) & \\
\hline \multicolumn{8}{|l|}{ General characteristics $^{b}$} \\
\hline Gender, males & 499 & (97) & 24 & $(100)$ & 34 & $(100)$ & - \\
\hline Age, years & 44.4 & $(9.2)$ & 49.2 & $(9.0)$ & 46.3 & $(9.5)$ & 0.029 \\
\hline Employed as fire-fighter, years & 16.3 & $(10.8)$ & 24.6 & $(10.0)$ & 20.0 & $(10.7)$ & $<0.001$ \\
\hline Height, $\mathrm{m}$ & 1.80 & $(6.8)$ & 1.80 & $(8.2)$ & 1.80 & $(6.0)$ & 0.986 \\
\hline Weight, kg & 88.8 & $(12.2)$ & 91.3 & $(14.3)$ & 91.1 & $(10.6)$ & 0.373 \\
\hline BMI, $\mathrm{kg} / \mathrm{m}^{2}$ & 27.3 & $(3.4)$ & 28.0 & $(3.3)$ & 28.0 & $(3.1)$ & 0.356 \\
\hline \multicolumn{8}{|l|}{ Smoking, $n(\%)$} \\
\hline Current & 23 & (4) & 1 & (4) & 3 & (9) & \\
\hline Former & 106 & (21) & 6 & (25) & 9 & (26) & \\
\hline Never & 383 & (75) & 17 & (71) & 22 & (65) & 0.708 \\
\hline \multicolumn{8}{|l|}{ Lung function ${ }^{c}$} \\
\hline $\mathrm{PEF}, \mathrm{L} / \mathrm{s}$ & 11.5 & $(2.0)$ & 11.0 & (3.2) & 11.4 & (2.4) & 0.634 \\
\hline $\mathrm{FEV}_{1}, \mathrm{~L}$ & 4.45 & $(0.67)$ & 4.14 & (1.18) & 4.41 & (1.18) & 0.450 \\
\hline$\%$ predicted & 112.5 & (12.8) & 107.6 & $(24.7)$ & 112.2 & (13.9) & 0.251 \\
\hline FVC, L & 5.88 & $(0.84)$ & 5.71 & $(1.32)$ & 5.79 & $(0.95)$ & 0.956 \\
\hline$\%$ predicted & 120.9 & $(12.5)$ & 119.5 & (20.5) & 119.2 & (12.8) & 0.683 \\
\hline $\mathrm{FEV}_{1} / \mathrm{FVC}, \%$ & 75.9 & $(6.2)$ & 72.3 & $(8.1)$ & 76.2 & $(5.9)$ & 0.063 \\
\hline $\mathrm{FEF}_{50}, \mathrm{~L} / \mathrm{s}$ & 4.77 & $(1.47)$ & 3.96 & $(2.01)$ & 4.88 & $(1.59)$ & 0.128 \\
\hline
\end{tabular}

Figures are means (standard deviation) unless stated otherwise

$B M I$ Body mass index, COPD chronic obstructive pulmonary disease, FEF50 forced expiratory flow at $50 \%$ of forced vital capacity, FEVI forced expiratory volume in $1 \mathrm{~s}, F V C$ forced vital capacity and $P E F$ peak expiratory flow

${ }^{\text {a }}$ Five fire-fighters who had asthma as well as doctor-diagnosed COPD/emphysema/bronchitis were analysed in the respiratory subgroup 'asthma'

${ }^{\mathrm{b}} p$ values are from univariate analyses ( $t$ tests, $\chi^{2}$ tests and Fisher's exact test)

${ }^{c} p$ values are from linear regression analysis, adjusted for age 
Schermer, T.R., Malbon, W., Morgan, M., Smith, M., Crockett, A.J. Chronic respiratory conditions in a cohort of metropolitan fire-fighters: associations with occupational exposure and quality of life. NPJ Primary Care Respiratory Medicine: 2017, 27(55), 919-928

Table 2 Involvement in fire-fighter tasks, types of fires attended and consistency in use of respiratory protection, and substances exposed to as a fire-fighter during the last 12 months

\begin{tabular}{|c|c|c|c|c|c|c|}
\hline & \multicolumn{6}{|c|}{ Respiratory health subgroups } \\
\hline & \multicolumn{2}{|c|}{$\begin{array}{l}\text { No chronic } \\
\text { respiratory } \\
\text { condition } \\
(n=512)\end{array}$} & \multicolumn{2}{|c|}{$\begin{array}{l}\text { Asthma }{ }^{b} \\
(n=24)\end{array}$} & \multicolumn{2}{|c|}{$\begin{array}{l}\text { COPD, } \\
\text { emphysema } \\
\text { or bronchitis } \\
(n=34)\end{array}$} \\
\hline \multicolumn{7}{|l|}{ Tasks involved in } \\
\hline Fire knockdown & 442 & (86) & 18 & (75) & 30 & (88) \\
\hline Consistent ${ }^{\mathrm{a}}$ use of protection & 308 & (70) & 12 & (67) & 22 & (73) \\
\hline Overhaul & 400 & (78) & 18 & (75) & 30 & $(88)$ \\
\hline Consistent ${ }^{\mathrm{a}}$ use of protection & 162 & (41) & 10 & (42) & 13 & (43) \\
\hline Fire investigation & 256 & (50) & 11 & (46) & 19 & (56) \\
\hline Consistent ${ }^{\mathrm{a}}$ use of protection & 46 & (18) & 2 & (18) & 6 & $(32)$ \\
\hline HazMat investigation & 241 & (47) & 10 & (42) & 19 & $(56)$ \\
\hline Consistent ${ }^{a}$ use of protection & 133 & (55) & 6 & $(60)$ & 10 & $(53)$ \\
\hline \multicolumn{7}{|c|}{ Types of fires attended } \\
\hline Residential fires & 472 & (92) & 22 & (92) & 30 & (88) \\
\hline Consistent ${ }^{\mathrm{a}}$ use of protection & 323 & (68) & 15 & (68) & 18 & $(60)$ \\
\hline Car fires & 452 & (88) & 19 & (79) & 30 & (88) \\
\hline Consistent ${ }^{\mathrm{a}}$ use of protection & 270 & $(60)$ & 11 & (58) & 15 & $(50)$ \\
\hline Dump or waste fires & 419 & (82) & 20 & (83) & 26 & (77) \\
\hline Consistent ${ }^{a}$ use of protection & 152 & (36) & 7 & (35) & 6 & (23) \\
\hline Commercial fires $^{c}$ & 361 & (71) & 20 & (83) & 24 & (71) \\
\hline Consistent ${ }^{\mathrm{a}}$ use of protection & 221 & (61) & 14 & (70) & 13 & (54) \\
\hline Industrial fires & 321 & (63) & 17 & (71) & 26 & (77) \\
\hline Consistent ${ }^{\mathrm{a}}$ use of protection & 172 & (54) & 11 & (65) & 12 & (46) \\
\hline Bush fires & 218 & (43) & 11 & (46) & 22 & $(65)$ \\
\hline Consistent use of protection & 32 & (15) & 1 & (9) & 0 & $(0)$ \\
\hline \multicolumn{7}{|l|}{ Substances exposed to } \\
\hline Smoke $^{\mathrm{d}}$ & 466 & (91) & 22 & (92) & 31 & (91) \\
\hline Vapours or fumes ${ }^{e}$ & 422 & (83) & 21 & (88) & 28 & $(82)$ \\
\hline Organic solvents ${ }^{\mathrm{f}}$ & 160 & (31) & 12 & (50) & 15 & (44) \\
\hline Organic dusts ${ }^{g}$ & 221 & (43) & 10 & (42) & 14 & (41) \\
\hline Inorganic dusts ${ }^{\mathrm{h}}$ & 246 & (48) & 15 & (63) & 12 & (35) \\
\hline
\end{tabular}

Figures are numbers (\%) within respiratory health subgroups. No statistically significant differences between the respiratory health subgroups were observed

a Consistent use of respiratory protection defined as self-reported use of respiratory protection during tasks in which exposed as either 'frequent' ( $80-100 \%$ of the time) or 'often' (60-80\% of the time)

${ }^{\text {b }}$ Five fire-fighters who had asthma as well as doctor-diagnosed COPD/ emphysema/chronic bronchitis were analysed in the asthma subgroup

'Shops/offices

${ }^{\mathrm{d}}$ Including particulate matter

'Engine exhausts, blasting fumes, carbon monoxide, methane, chlorine, ammonia, etc.

${ }^{\mathrm{f}}$ Benzene, aldehydes, isocyanates, formaldehyde, industrial cleaning products, etc.

${ }^{g}$ Grains, animal feeds, textile dust, sawdust, moulds, etc.

${ }^{\text {h }}$ Coal dust. cement dust. silica. sand. asbestos. fibreglass. etc. 
Schermer, T.R., Malbon, W., Morgan, M., Smith, M., Crockett, A.J. Chronic respiratory conditions in a cohort of metropolitan fire-fighters: associations with occupational exposure and quality of life. NPJ Primary Care Respiratory Medicine: 2017, 27(55), 919-928

Fig. 1 Mean physical (PCS-12, panel $A$ ) and mental (MCS-12, panel $B$ ) SF-12 component summary scores in fire-fighters in the respiratory health subgroups in relation to exposure protection categories. Bars indicated standard deviations
Not involved in knockdown $\square \begin{aligned} & \text { Involved in knockdown, } \\ & \text { consistent use of respiratory protection }\end{aligned}$ Involved in knockdown, inconsistent use of respiratory protection
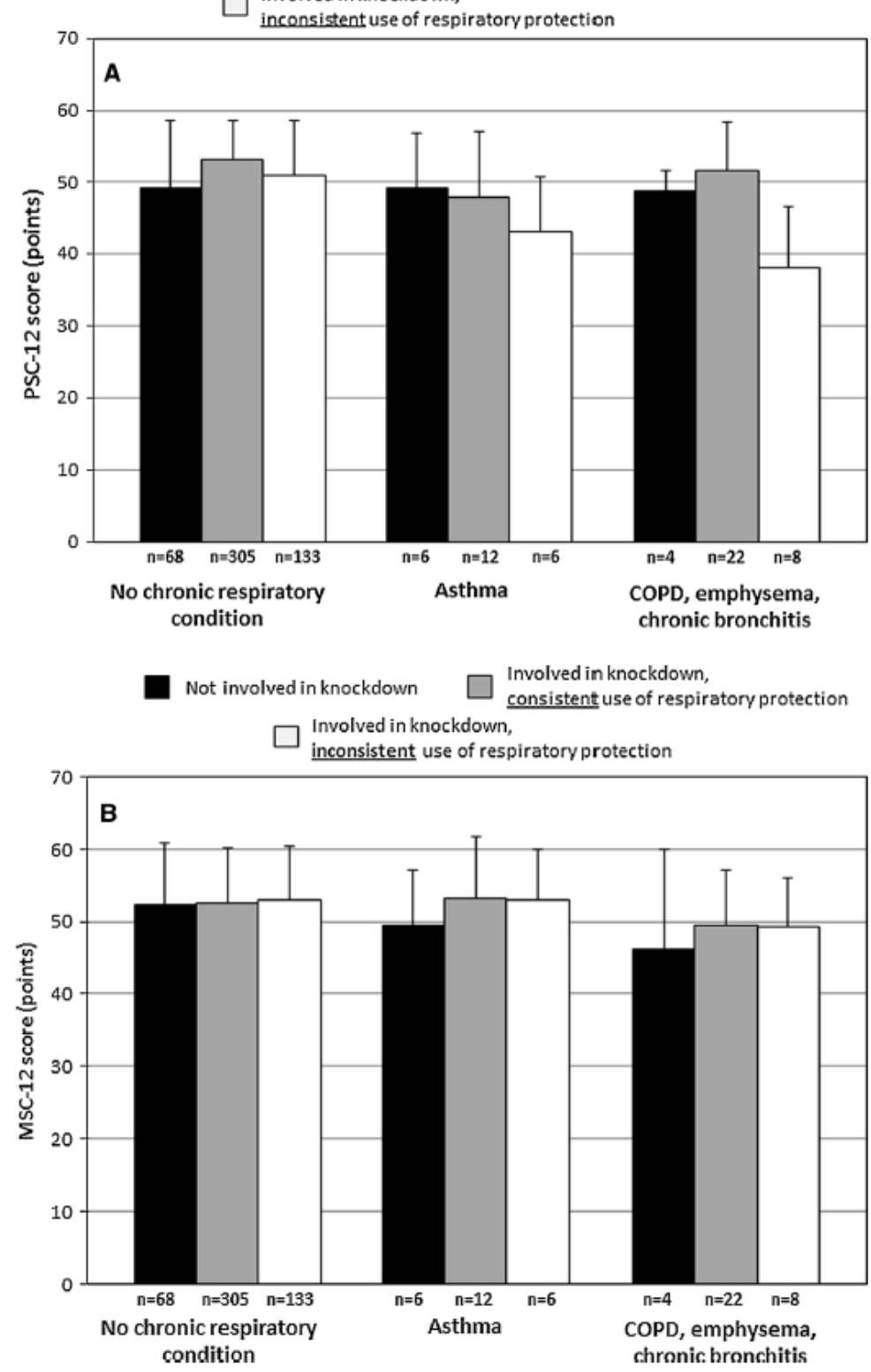
Schermer, T.R., Malbon, W., Morgan, M., Smith, M., Crockett, A.J. Chronic respiratory conditions in a cohort of metropolitan fire-fighters: associations with occupational exposure and quality of life. NPJ Primary Care Respiratory Medicine: 2017, 27(55), 919-928

Table 3 Results from linear regression models for physical (PCS) and mental (MCS) SF-12 component summary scores for fire-fighters with and without chronic respiratory conditions in relation to self-reported protection from occupational exposure

\begin{tabular}{|c|c|c|c|c|c|c|}
\hline & \multicolumn{3}{|l|}{ PCS-12 } & \multicolumn{3}{|l|}{ MCS-12 } \\
\hline & $\begin{array}{l}\beta \\
\text { coefficient }\end{array}$ & $95 \%$ CI & $p$ & $\begin{array}{l}\beta \\
\text { coefficient }\end{array}$ & $95 \% \mathrm{CI}$ & $p$ \\
\hline Intercept & 52.87 & $52.14 ; 53.59$ & $<0.001$ & 52.85 & $51.97 ; 53.74$ & $<0.001$ \\
\hline Chronic respiratory condition ${ }^{\mathrm{a}}$ (A) (yes vs. no) & -0.32 & $-1.59 ; 0.96$ & 0.625 & -1.04 & $-2.61 ; 0.52$ & 0.190 \\
\hline $\begin{array}{l}\text { Involved in knockdown, consistent use of respiratory protection } \\
\text { (B) (yes vs. no) }\end{array}$ & 0 & - & - & 0 & - & - \\
\hline $\begin{array}{l}\text { Involved in knockdown, inconsistent use of respiratory protection } \\
\text { (C) (yes vs. no) }\end{array}$ & -0.89 & $-2.20 ; 0.41$ & 0.179 & 0.79 & $-0.81 ; 2.39$ & 0.330 \\
\hline Not involved in knockdown (D) (yes vs. no) & -1.19 & $-2.86 ; 0.49$ & 0.165 & 0.63 & $-1.42 ; 2.68$ & 0.546 \\
\hline Chronic respiratory condition ${ }^{*}$ consistent use $\left(\mathbf{A}^{*} \mathbf{B}\right)$ & 0 & - & - & 0 & - & - \\
\hline Chronic respiratory condition $*$ inconsistent use $\left(\mathbf{A}^{*} \mathbf{C}\right)$ & -5.54 & $-7.95 ;-3.13$ & $<0.001$ & -0.09 & $-3.04 ; 2.87$ & 0.954 \\
\hline Chronic respiratory condition $*$ not involved $\left(\mathbf{A}^{*} \mathbf{D}\right)$ & 0.96 & $-2.08 ; 4.00$ & 0.536 & -1.15 & $-4.87 ; 2.57$ & 0.545 \\
\hline $\operatorname{Age}^{c}(1$ year older $)$ & -0.15 & $-0.21 ;-0.08$ & $<0.001$ & -0.05 & $-0.13 ; 0.03$ & 0.211 \\
\hline $\mathrm{BMI}^{\mathrm{c}}$ (one $\mathrm{kg} / \mathrm{m}^{2}$ more) & -0.53 & $-0.69 ;-0.36$ & $<0.001$ & 0.03 & $-0.17 ; 0.22$ & 0.802 \\
\hline Other relevant medical conditions ${ }^{\mathrm{d}}$ & -6.15 & $-7.83 ;-4.47$ & $<0.001$ & -4.59 & $-6.65 ;-2.53$ & $<0.001$ \\
\hline
\end{tabular}

$B M I$ body mass index, $C I$ confidence interval and $C O P D$ chronic obstructive pulmonary disease

${ }^{\text {a }}$ Asthma and $\mathrm{COPD} / \mathrm{emphysema/chronic} \mathrm{bronchitis} \mathrm{subgroups} \mathrm{combined}$

b This subgroup serves as the reference group in the analysis

${ }^{c}$ In order to maintain interpretability of the coefficients in the linear regression model, continuous variables were cantered by subtracting the group mean PCS-12 and MCS-12 values from each fire-fighter's individual values

${ }^{\mathrm{d}}$ Cardiovascular (myocardial infarction, angina pectoris, heart failure and stroke); diabetes mellitus; locomotor conditions; recent pneumonia; and other (single cases of prostate cancer; Crohn's disease; renal dysfunction; myeloma; sleep apnoea; and mental illness ) 